\title{
PIRÓLISE DA CASCA DE MACADÂMIA: INVESTIGAÇÃO DE VARIÁVEIS OPERACIONAIS
}

\author{
F. B. SANTOS ${ }^{1}$, C. G. FERREIRA ${ }^{1}$, L. V. CRISSAFF ${ }^{1}$, T. P. XAVIER ${ }^{1,2}$ e T. S. LIRA ${ }^{1,2}$
}

${ }^{1}$ Universidade Federal do Espírito Santo, Departamento de Engenharias e Tecnologias

${ }^{2}$ Universidade Federal do Espírito Santo, Programa de Pós-graduação em Energia

E-mail para contato: taisa.lira@ufes.br

\begin{abstract}
RESUMO - A busca por fontes energéticas de origem renovável, sustentável e de baixo custo, tem estimulado o desenvolvimento de processos capazes de transformar biomassa em produtos substituintes dos derivados de petróleo. A pirólise é uma alternativa viável, capaz de converter a biomassa lignocelulósica em produtos sólidos (carvão), líquidos (bio-óleo) e gasosos. O bio-óleo pode ser utilizado como substituinte de combustíveis tradicionais, o que implica o crescente interesse neste produto. Ademais, o rendimento destes três produtos é altamente influenciado pelas condições do processo. Portanto, o objetivo deste trabalho foi estudar a pirólise lenta da casca de macadâmia em leito fixo. Para isto foi realizado um planejamento experimental $3^{2} \mathrm{com}$ mais dois pontos centrais, tendo como variáveis-resposta o rendimento dos produtos: solido, líquido e gasoso, em função da temperatura e da taxa de aquecimento. $\mathrm{O}$ procedimento experimental permitiu observar que os rendimentos da fração líquida e sólida aumentam em menores temperaturas e taxas de aquecimento, sendo que, para fração gasosa, o comportamento foi contrário.
\end{abstract}

\section{INTRODUÇÃO}

O desenvolvimento de combustíveis limpos e a busca por fontes alternativas de energia são alguns dos maiores desafios a serem enfrentados pela sociedade moderna para que a meta de desenvolvimento sustentável seja atingida. Nesse contexto, a biomassa surge como uma oportunidade viável ambiental e economicamente.

O fruto da macadâmia é composto por três partes: amêndoa (embrião), casca (endocarpo) e carpelo (exocarpo e mesocarpo). O beneficiamento da macadâmia gera, além da amêndoa, principal produto comercial, 70-77\% de resíduos (casca e carpelo) (PIMENTEL, 2007).

Um dos principais métodos utilizados na conversão termoquímica de biomassa é a pirólise (ou suas variações: liquefação, gaseificação e carbonização). É um processo de decomposição termoquímica que ocorre na ausência total de oxigênio ou uma quantidade significativamente menor que a necessária para uma combustão completa.

No processo de pirólise, inicialmente, formam-se os gases condensáveis e o carvão. Posteriormente, os gases condensáveis decompõem-se em gases não condensáveis e um 
fração líquida. A mistura líquida possui duas fases, uma aquosa (extrato ácido) e outra orgânica (bio-óleo), deixando os gases não condensáveis, geralmente $\mathrm{CO}_{2}, \mathrm{CO}, \mathrm{CH}_{4}, \mathrm{H}_{2}$, como combustível para uso imediato. Nos sólidos encontram-se o carvão e as cinzas (DI BLASI, 2008).

O produto líquido dos processos de pirólise pode ser utilizado em forma de combustível, pois apresenta uma mistura de compostos orgânicos de alto valor energético, que podem ser utilizados para geração de energia em motores e turbinas. Além disso, também podem ser usados como fonte de substâncias químicas puras, tais como álcool, fenol, aldeído, ácidos orgânicos, entre outros (GONÇALVES, 2014).

Além da taxa de aquecimento, outras são as condições operacionais variáveis do processo de pirólise, como a temperatura final atingida, tamanho das partículas de biomassa e o tempo de residência das fases sólida e gasosa no reator. Tais variáveis irão influenciar diretamente no rendimento do produto final do processo (GÓMEZ, 2003).

Com o intuito de contribuir para o estudo das condições experimentais da pirólise, o presente trabalho propõe estimar o efeito da temperatura e da taxa de aquecimento nos rendimentos dos produtos sólidos, líquidos e gasosos do processo de pirólise em leito fixo da casca de macadâmia.

\section{METODOLOGIA}

\subsection{Material}

As cascas da macadâmia, cujas propriedades são apresentadas na Tabela 1 (XAVIER, 2016), foram fornecidas pela Cooperativa Agroindustrial dos Produtores de Noz Macadâmia (COOPMAC), situada no município de São Mateus - ES.

Tabela 1 - Propriedades químicas e físicas da casca de macadâmia.

\begin{tabular}{|c|c|c|c|}
\hline \multicolumn{4}{|c|}{ Análise elementar } \\
\hline \multicolumn{2}{|c|}{ Carbono $(\%)$} & \multicolumn{2}{|c|}{47,89} \\
\hline \multicolumn{2}{|c|}{ Hidrogênio (\%) } & \multicolumn{2}{|c|}{5,82} \\
\hline \multicolumn{2}{|c|}{ Nitrogênio (\%) } & \multicolumn{2}{|c|}{0,15} \\
\hline \multicolumn{2}{|c|}{ Enxofre (\%) } & \multicolumn{2}{|c|}{0,79} \\
\hline \multicolumn{2}{|c|}{ Oxigênio (\%) } & \multicolumn{2}{|c|}{45,13} \\
\hline \multicolumn{2}{|c|}{ Composição lignocelulósica } & \multicolumn{2}{|c|}{ Análise imediata } \\
\hline Extrativos (\%) & 14,2 & Umidade (\%) & 10,47 \\
\hline Lignina $(\%)$ & 42,3 & Voláteis (\%bs) & 80,99 \\
\hline Hemicelulose $(\%)$ & 13,2 & Cinzas (\%bs) & 0,22 \\
\hline Celulose $(\%)$ & 30,3 & Carbono fixo (\%bs & 18,74 \\
\hline \multicolumn{4}{|c|}{ Propriedades físicas } \\
\hline \multicolumn{2}{|c|}{ Massa específica real $\left[\mathrm{kg} / \mathrm{m}^{3}\right]$} & \multicolumn{2}{|c|}{1450} \\
\hline \multicolumn{2}{|c|}{ Diâmetro médio [m] } & \multicolumn{2}{|c|}{$1,55_{\mathrm{x}} 10^{-3}$} \\
\hline
\end{tabular}




\subsection{Procedimento Experimental}

As reações de pirólise da casca de macadâmia foram conduzidas em um reator tubular de quartzo instalado em um Forno Tubular Bipartido Fortlab modelo FT 1200 H/V. Utilizouse aproximadamente $50 \mathrm{~g}$ de amostra em cada reação, que foi conduzida a pressão atmosférica e sob fluxo de gás $\mathrm{N}_{2}(200 \mathrm{~mL} / \mathrm{min})$.

Uma matriz de planejamento de experimentos (Tabela 2) foi montada para investigar os efeitos da temperatura e da taxa de aquecimento na reação de pirólise da casca de macadâmia em leito fixo. Como variáveis-resposta foram analisados os rendimentos dos produtos: sólido, líquido e gasoso.

Tabela 2 - Matriz do planejamento fatorial $3^{2}$ com mais dois pontos centrais.

\begin{tabular}{c|c|c}
\hline Experimento & Temperatura $\left({ }^{\mathbf{0}} \mathbf{C}\right)$ & Taxa $\left({ }^{\mathbf{0}} \mathbf{C} \mathbf{m i m}\right)$ \\
\hline 1 & 450 & 20 \\
\hline 2 & 450 & 60 \\
\hline 3 & 450 & 100 \\
\hline 4 & 550 & 20 \\
\hline 5 & 550 & 60 \\
\hline 6 & 550 & 200 \\
\hline 7 & 650 & 60 \\
\hline 8 & 650 & 100 \\
\hline 9 & 650 & 60 \\
\hline 10 & 550 & 60 \\
\hline 11 & 550 & 00 \\
\hline
\end{tabular}

Ao atingir a temperatura de pirólise, a temperatura final foi mantida por 30 minutos. Os produtos voláteis produzidos foram condensados e recolhidos em dois frascos Kitassatos, em banho de gelo, e foram denominados de líquido de pirólise. Os gases não condensáveis foram passados por lavagem em água e descartados para a atmosfera. Após o término da pirólise o reator foi retirado do forno e resfriado, sob fluxo de nitrogênio até chegar à temperatura inferior a $60^{\circ} \mathrm{C}$. Os percentuais de rendimento em massa do carvão, líquido e gases da pirólise foram determinados conforme as Equações 1, 2 e 3, respectivamente.

$$
\begin{gathered}
\% \text { Sólido }=\left(m_{\text {sólido }} / m_{\text {casca }}\right) * 100 \\
\% \text { Líquido }=\left(m_{\text {líquido }} / m_{\text {casca }}\right) * 100 \\
\% \text { Gases }=100-(\% \text { Sólido }+\% \text { Líquido })
\end{gathered}
$$

\section{RESULTADOS E DISCUSSÃO}

As Tabelas 3, 4 e 5 contêm os resultados obtidos pela análise dos efeitos, a partir do software STATISTICA, considerando apenas os termos que influenciaram significativamente o rendimento da fração sólida, líquida e gasosa, respectivamente, da pirólise da casca de macadâmia. A determinação dos parâmetros significativos foi realizada por meio de um teste de hipótese utilizando a distribuição $t$-Student com nível de significância de $95 \%$. Os parâmetros, com nível de significância menor que este valor, foram desconsiderados. 
$\mathrm{Na}$ Tabela 3, observa-se que os efeitos das variáveis isoladas (temperatura e taxa de aquecimento) foram significativos e modificaram-se inversamente em relação a variável resposta, portanto, os maiores rendimentos para fração sólida são obtidos utilizando-se menores temperaturas e taxas de aquecimento, como mostra a superfície de resposta, disposta na Figura 1.

Tabela 3 - Efeitos da temperatura e taxa de aquecimento sobre a o rendimento da fração sólida $\left(\mathrm{R}^{2}=0,98\right)$.

\begin{tabular}{c|c|c|c}
\hline Fator & Efeito & Desvio & p-valor \\
\hline Média & 27,91 & 0,13 & $<0,00$ \\
\hline Temperatura $(\mathrm{T})$ & $-5,99$ & 0,32 & $<0,00$ \\
\hline Temperatura ${ }^{2}\left(\mathrm{~T}^{2}\right)$ & $-0,74$ & 0,26 & 0,03 \\
\hline Taxa $(\mathrm{X})$ & $-0,84$ & 0,36 & 0,05 \\
\hline
\end{tabular}

Figura 1 - Superfície de resposta para rendimento da fração sólida do produto de pirólise em função da temperatura e da taxa de aquecimento.

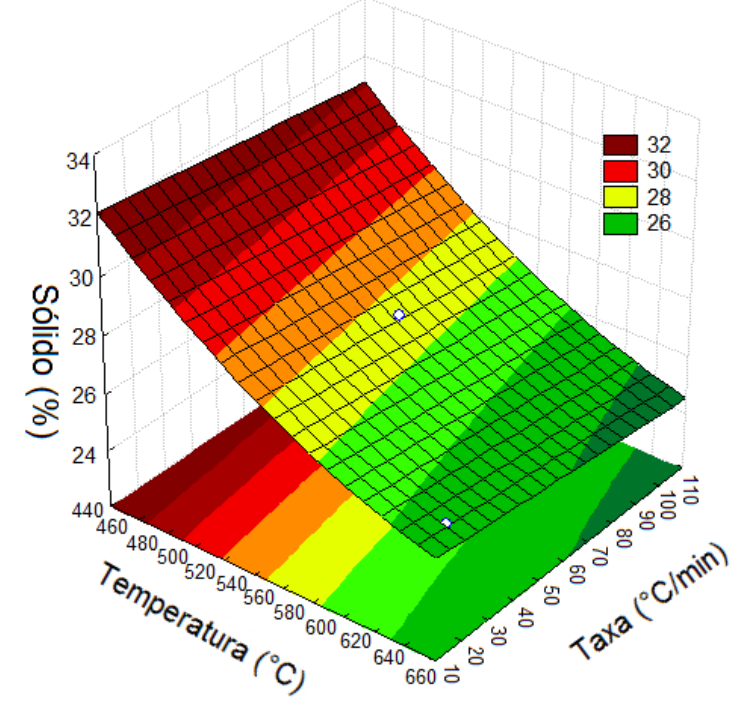

$\mathrm{Na}$ Tabela 4, além dos efeitos das variáveis isoladas, a interação entre as duas variáveis também foi significativa. Vale ressaltar que o baixo valor referente ao $\mathrm{R}^{2}$ pode ter ocorrido em detrimento de perdas da fração líquido no decorrer da pirólise que impossibilitaram a obtenção de medidas mais acuradas. A Figura 2 ilustra a superfície resposta para o rendimento da fração líquida. Observa-se que os maiores rendimentos de líquidos são obtidos com níveis de temperaturas e taxa de aquecimentos baixos.

Tabela 4 - Efeitos da temperatura e taxa sobre a o rendimento da fração líquida $\left(R^{2}=0,86\right)$.

\begin{tabular}{c|c|c|c}
\hline Fator & Efeito & Desvio & p-valor \\
\hline Média & 53,10 & 0,15 & $<0,00$ \\
\hline Temperatura (T) & $-1,08$ & 0,38 & 0,03 \\
\hline Taxa (X) & $-1,92$ & 0,42 & $<0,00$ \\
\hline Interação (T. X) & $-1,40$ & 0,47 & 0,02 \\
\hline
\end{tabular}


Figura 2 - Superfície de resposta para rendimento da fração líquida do produto de pirólise em função da temperatura e da taxa de aquecimento.

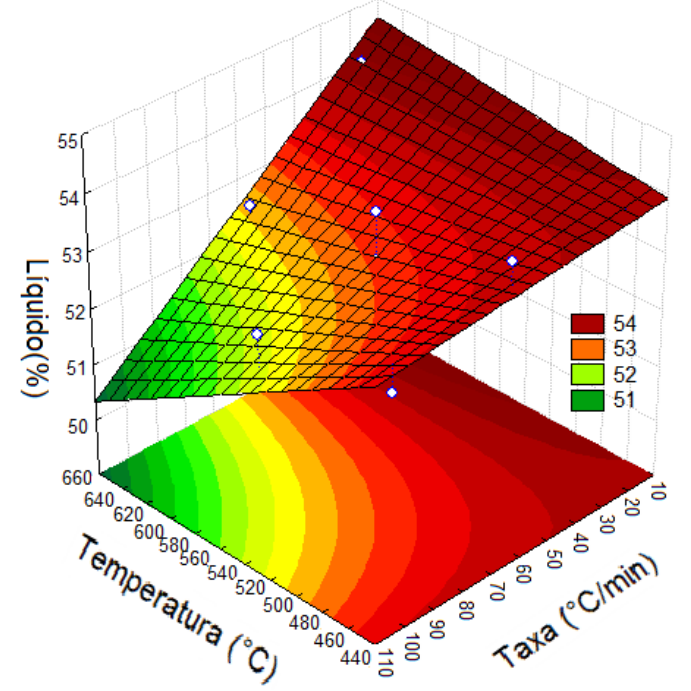

$\mathrm{Na}$ Tabela 5, é salientado que o rendimento da fração gasosa varia diretamente em relação aos efeitos das variáveis independentes e da interação entre estas. Nota-se que este rendimento também é mais sensível a variações da temperatura, como ilustrado na superfície resposta, disposta na Figura 3.

Tabela 5 - Efeitos da temperatura e taxa sobre a o rendimento da fração gasosa $\left(R^{2}=0,97\right)$.

\begin{tabular}{c|c|c|c}
\hline Fator & Efeito & Desvio & p-valor \\
\hline Média & 19,03 & 0,20 & $<0,00$ \\
\hline Temperatura (T) & 7,07 & 0,52 & $<0,00$ \\
\hline Taxa (X) & 2,94 & 0,57 & $<0,00$ \\
\hline Interação (T. X) & 1,84 & 0,64 & 0,03 \\
\hline
\end{tabular}

Figura 3 - Superfície de resposta para rendimento da fração gasosa do produto de pirólise em função da temperatura e da taxa de aquecimento.

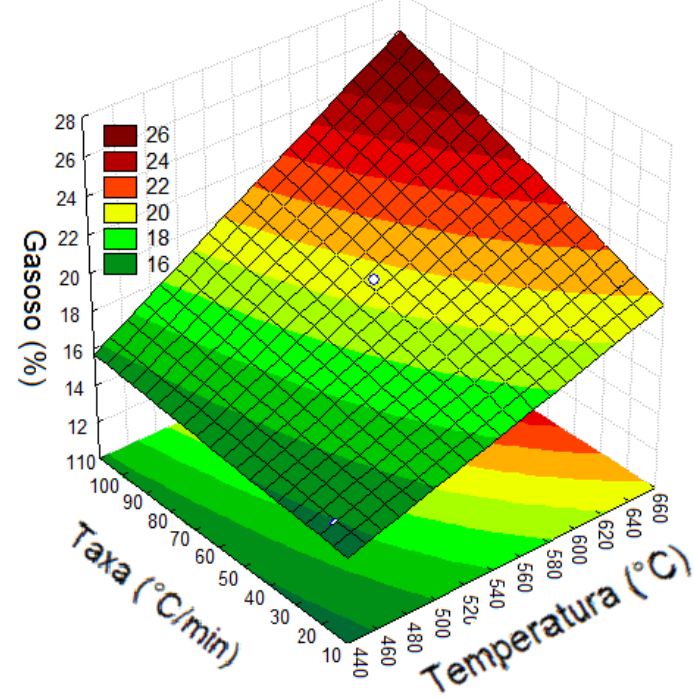




\section{CONCLUSÕES}

Os ensaios de pirólise da biomassa com diferentes taxas de aquecimento apresentaram pequena variação no rendimento dos produtos, a mesma observação é inversa quando se trata da temperatura. $\mathrm{O}$ maior rendimento de bio-óleo $(55,32 \%)$ foi obtido nas condições de $550^{\circ} \mathrm{C}$ e na taxa de aquecimento de $20^{\circ} \mathrm{C} / \mathrm{min}$. O bio-óleo da pirólise da casca de macadâmia apresentou uma mistura heterogênea (fase aquosa e orgânica) com predominância da fase aquosa. Observou-se que o rendimento de carvão (produto sólido) foi favorecido para os menores valores das variáveis independentes, já o rendimento gasoso foi favorecido para maiores condições de temperatura e taxa de aquecimento.

Com base nos resultados e observações apresentados neste trabalho, conclui-se que a casca de macadâmia apresentou-se como uma fonte promissora para aplicação em processos de pirólise para obtenção de líquidos condensáveis (bio-óleo) e carvão.

\section{REFERÊNCIAS}

PIMENTEL, L. D. A cultura da macadâmia. Revista Brasileira de Fruticultura, v. 29, p. 414716, 2007.

DI BLASI, C. Modeling chemical and physical processes of wood and biomass pyrolysis. Progress in Energy and Combustion Science, v. 34, p. 47-90, 2008.

GONÇALVES, G. C. Estudo da pirólise do bagaço de malte para a obtenção de bio-óleo e carvão. Universidade Tecnológica Federal do Paraná, Campus Toledo, 2014.

GÓMEZ, E. O.; PÉREZ, J. M. M.; SEYE, O.; LINERO, F. A. B. Projeto de pirólise rápida contínua de biomassa com ar em reator de leito fluidizado atmosférico. Scielo Poceedings, An.3.Enc.Energ. Meio Rural, 2003.

XAVIER, T. P. Contribuições para a pirólise da casca de macadâmia em leito de jorro cônico. 2016. 162 f. Tese (Doutorado em Engenharia Química) - Programa de Pósgraduação em Engenharia Química, Universidade Federal de Uberlândia (UFU), Uberlândia, 2016. 